\title{
A tertiary interaction in the Tetrahymena intron contributes to selection of the $5^{\prime}$ splice site
}

\author{
William D. Downs ${ }^{1}$ and Thomas R. Cech ${ }^{2}$ \\ Department of Molecular, Cellular, and Developmental Biology, Department of Chemistry and Biochemistry, Howard \\ Hughes Medical Institute, University of Colorado, Boulder, Colorado 80309-0215 USA
}

The utilization of cryptic splice sites has been observed in a number of RNA splicing reactions. In the self-splicing group I intron of Tetrahymena thermophila, point mutations of either $A_{57}$ or $A_{95}$ promote cleavage at two sites other than the normal $5^{\prime}$ splice site, suggesting that these nucleotides are involved in a common tertiary interaction. These results are unusual since $A_{57}$ and $A_{95}$ are neither at nor near the $5^{\prime}$ splice site in the sequence or secondary structure. Cleavage at the alternative sites appears to occur by intron cyclization, a reaction with well-established structural and mechanistic similarities to the first step of RNA self-splicing. Alternative docking of P1 (the helix containing the $5^{\prime}$ splice site paired to the internal guide sequence of the intron) into the catalytic core accounts for cleavage at the cryptic reaction sites. We propose that the $A_{57} / A_{95}$ interaction, along with an element implicated previously (J1/2), provide structural connectivity from the reaction site in P1 to the catalytic core of the Tetrahymena intron. It seems likely that RNA splicing in general will require such tertiary interactions to position RNA helices.

[Key Words: Accuracy; group I introns; photo-cross-linking; ribozyme; RNA splicing; RNA tertiary structure] Received March 11, 1994; revised version accepted April 12, 1994.

In spliceosomal mRNA splicing and in self-splicing, RNA makes up part or all of the splicing machinery. In each case, the first chemical step is cleavage at the $5^{\prime}$ splice site, a reaction that must occur with high accuracy. Our understanding of $5^{\prime}$ splice site selection has focused on base-pairing interactions, and in each case RNA components of the splicing machinery have been found to provide binding sites or "guide sequences" that base-pair with sequence flanking the $5^{\prime}$ splice site. In group I and group II self-splicing reactions, the introns themselves provide the base-pairing sequences (Davies et al. 1982; Michel and Dujon 1983; Michel et al. 1989b). In nuclear mRNA splicing the initial recognition is by the U1 small nuclear RNA (snRNA) (Lerner et al. 1980; Zhuang and Weiner 1986; Guthrie 1991), later to be replaced by base-pairing with U5 and U6 snRNAs (Kandels-Lewis and Séraphin 1993; Lesser and Guthrie 1993; Sontheimer and Steitz 1993). Whereas these base-pairing interactions are necessary to direct the first step of splicing, it seems unlikely that they alone could ensure accuracy; once the splice-site duplex is formed, some mechanism is needed to align it with respect to the attacking group, which is contained in a second RNA du-

'Present address: Fred Hutchinson Cancer Research Center, Seattle, Washington 98104 USA.

${ }^{2}$ Corresponding author. plex (P7 in group I introns, domain VI in group II introns, the U2 snRNA - branch site duplex in nuclear mRNA introns). We now identify a tertiary interaction in the Tetrahymena group I intron that helps to provide this next level of accuracy by holding the $5^{\prime}$ splice-site duplex into the proper position for splicing.

Self-splicing of the Tetrahymena pre-rRNA and cyclization of the excised intron occur in three steps, each involving the same chemical mechanism of transesterification (Cech and Bass 1986; Cech 1990). The 5' splice site is contained within the Pl helix, which consists of $5^{\prime}$ exon sequence paired with the internal guide sequence (IGS) of the intron (Davies et al. 1982). The P1 duplex is held in the active site of the intron and cleaved at the $5^{\prime}$ splice site during the first step of splicing (Doudna et al. 1989; Pyle et al. 1992). Guanosine (or GMP, GDP, or GTP) from solution is also bound in the active site of the intron (Michel et al. 1989a), and its 3' OH group carries out this cleavage resulting in addition of the guanosine to the $5^{\prime}$ end of the intron (Cech et al. 1981) (Fig. 1). In the second step of splicing, another transesterification reaction separates the intron from the $3^{\prime}$ exon and at the same time joins the $5^{\prime}$ and $3^{\prime}$ exons. Then, in a final reaction, the guanosine at the extreme $3^{\prime}$ end of the excised intron carries out an intramolecular nucleophilic attack at a site near the $5^{\prime}$ end of the intron. As in the first step of splicing, this reaction site follows an oligopyrimidine sequence that is selected by base-pairing to a 


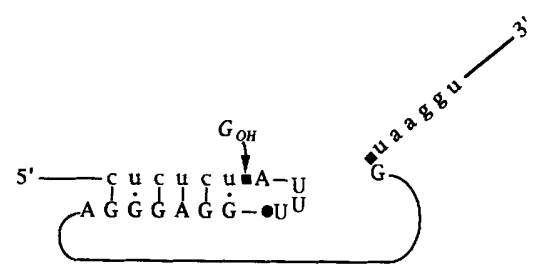

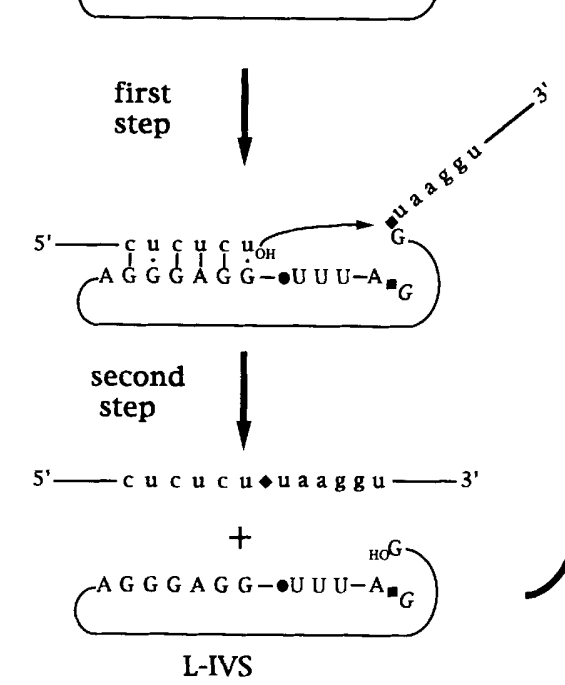

L-IVS

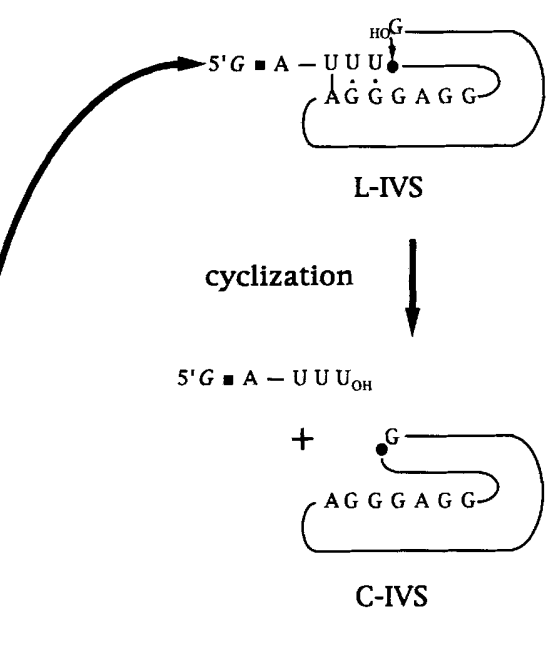

Figure 1. Self-processing of the Tetrahymena group I intron. Shown are the three transesterification reactions of processing: the first step of splicing, the second step of splicing, and cyclization of the excised linear intron (L-IVS). Each image emphasizes the IGS $\left(3^{\prime}\right.$-AGGGAGG-5' $)$ and the duplex in which it participates in that stage of reaction. Arrows indicate nucleophilic attack of a phosphorous atom by a $3^{\prime}$ hydroxyl group. The phosphates existing at points of cleavage are marked: (D) 5 ' splice site; $\left(\bullet / 3^{\prime}\right.$ splice site; (O) cyclization site. The intron sequence is in uppercase letters; exons are in lowercase letters. portion of the IGS (Been and Cech 1987). The result is the conversion of the intron to a circular form.

Previously, cross-linking studies revealed that nucleotides $\mathrm{A}_{57}$ and $\mathrm{A}_{95}$ are proximal to one another in both the unspliced precursor of the Tetrahymena rRNA (Downs 1993) and a shortened version of the intron with enzymatic activity (Downs and Cech 1990). The occurrence of this UV-inducible cross-link suggested that the bases of the two nucleotides can stack upon one another in the three-dimensional structure, and the properties of the cross-linking reaction indicated that this structure is characteristic of the active molecule. Now, to investigate the functional contribution of these nucleotides, $A_{57}$ and $A_{95}$ have been individually mutated. In the mutant RNAs cleavage occurs at two sites other than the normal $5^{\prime}$ splice site. The observation that mutating either $A_{57}$ or $A_{95}$ results in the same phenotype of inaccurate reaction suggests that these nucleotides take part in a common function of choosing a $5^{\prime}$ splice site.

\section{Results}

Testing the importance of $A_{57}$ and $A_{95}$ in selfsplicing

Point mutations at positions $\mathrm{A}_{57}$ and $\mathrm{A}_{95}$ were introduced into a DNA template encoding a portion of the Tetrahymena rRNA precursor. Five of these six mutations eliminate cross-linking in the rRNA precursor. The sixth mutant, A57G, can still cross-link but at less than half the rate of the wild-type precursor (data not shown). The sites of $A_{57}$ and $A_{95}$ are shown in Figure 2 in the context of the secondary structure of the intron. The self-processing of precursor RNA transcribed from each of these templates was examined under three different conditions that favor different reactions of the RNA: splicing, specific hydrolysis at the splice site, and cyclization of the excised intron (Been and Cech 1986). The effect of cross-linking $A_{57}$ and $A_{95}$ in the wild-type precursor was examined in parallel.

Splicing conditions include a low concentration of $\mathrm{MgCl}_{2}(3 \mathrm{~mm})$, a low temperature of incubation $\left(30^{\circ} \mathrm{C}\right)$, and the presence of guanosine $(200 \mu \mathrm{M})$ in the reaction. Under these conditions, the overall activity of all the mutants is lowered relative to wild type (Fig. 3a). However, those mutants that still undergo splicing generate the same products that are generated by the wild-type precursor: linear intron (L-IVS), ligated exons, and small amounts of $5^{\prime}$ exon.

Site-specific hydrolysis conditions involve a higher concentration of $\mathrm{MgCl}_{2}(10 \mathrm{~mm})$ and a higher temperature of incubation $\left(42^{\circ} \mathrm{C}\right)$, but guanosine is not present. These conditions were included to evaluate the ability of the intron to activate the splice sites in the absence of the normal nucleophile, guanosine (Inoue et al. 1986). In the mutants and the cross-linked precursor, these conditions produced three aberrant species-5'ex-4, $5^{\prime}$ ex +14 , and LE +14 (where $5^{\prime}$ ex is $5^{\prime}$ exon and LE is ligated exons; Fig. 31-in addition to the normal splicing products.

Cyclization conditions, which promote pre-rRNA splicing as well as intron cyclization, are the same as hydrolysis conditions except that guanosine $(200 \mu \mathrm{M})$ is also present. The addition of guanosine appears to increase the overall extent of reaction but also results in lower yields of the aberrant products $\left(\mathrm{LE}+14,5^{\prime} \mathrm{ex}+14\right.$, 
Figure 2. The Tetrahymena intron. The secondary structure of the intron $1 \mathrm{Cech}$ 1990; Michel and Westhof 1990) is outlined, and those sequences discussed in the text are superimposed. Labeled arrows mark sites of phosphodiester linkages that can serve as points of cleavage during selfprocessing of mutant and cross-linked precursors. The broken lines labeled ScaI and $\omega \mathrm{G}$ mark the $3^{\prime}$ termini of two truncated forms of the pre-rRNA used in this investigation (see Fig. 7).

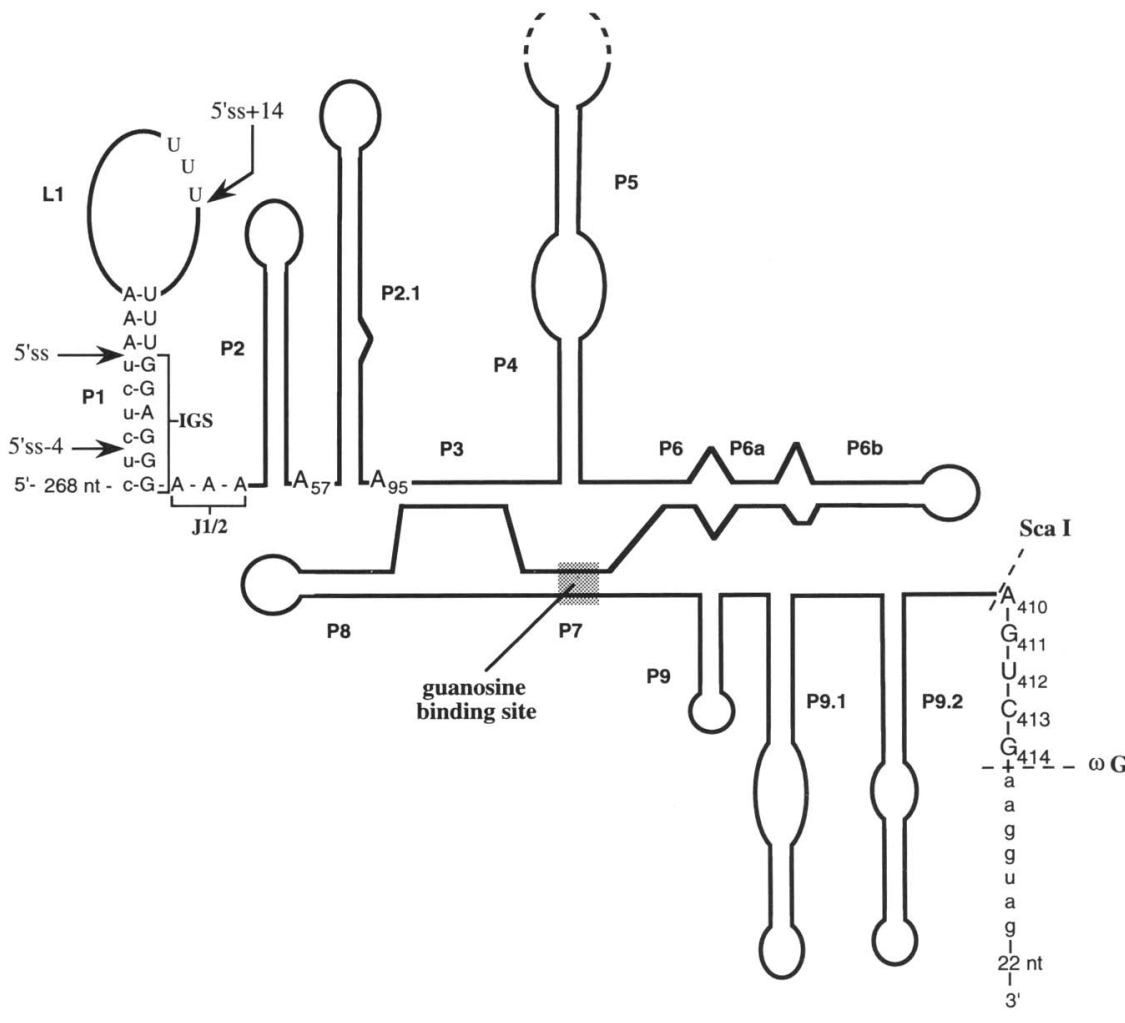

rant products indicates that guanosine from solution is not required for these alternative reactions. The yield of the aberrant products is actually reduced under cyclization conditions, as if normal splicing that uses exogenous guanosine competes with the aberrant reactions of the precursor. This suggests that all three aberrant products are actually the result of cleavage by another nucleophile, even in the presence of guanosine.

\section{$A_{57}$ and $A_{95}$ contribute structural stability}

The phenotypes of the $A 57 \mathrm{~N}, \mathrm{~A} 95 \mathrm{~N}$, and cross-linked precursors appear to be attributable to a structural defect. When more $\mathrm{MgCl}_{2}$ is included in the reaction (hydrolysis or cyclization conditions), activity is increased (Fig. 3). The restoration of activity with higher concentrations of magnesium cation has been observed in a number of mutants of the Tetrahymena intron (Burke et al. 1986; Flor et al. 1989; Joyce et al. 1989) and has been attributed to the stabilization of a destabilized structure. Also, an RNA enzyme derived from the Tetrahymena intron retains its ability to cleave an RNA substrate even after the $A_{57}-A_{95}$ cross-link has been introduced (W. Downs and T. Cech, unpubl.). However, this activity is lost when the reaction solution contains $2 \mathrm{M}$ urea (Downs and Cech 1990), an amount of denaturant that does not interfere with substrate cleavage in the uncrosslinked ribozyme (Zaug et al. 1988).

When the relative activities of the different mutants under splicing conditions are compared (Fig. 3a), two general trends are observed. Mutations of $A_{95}$ generally 


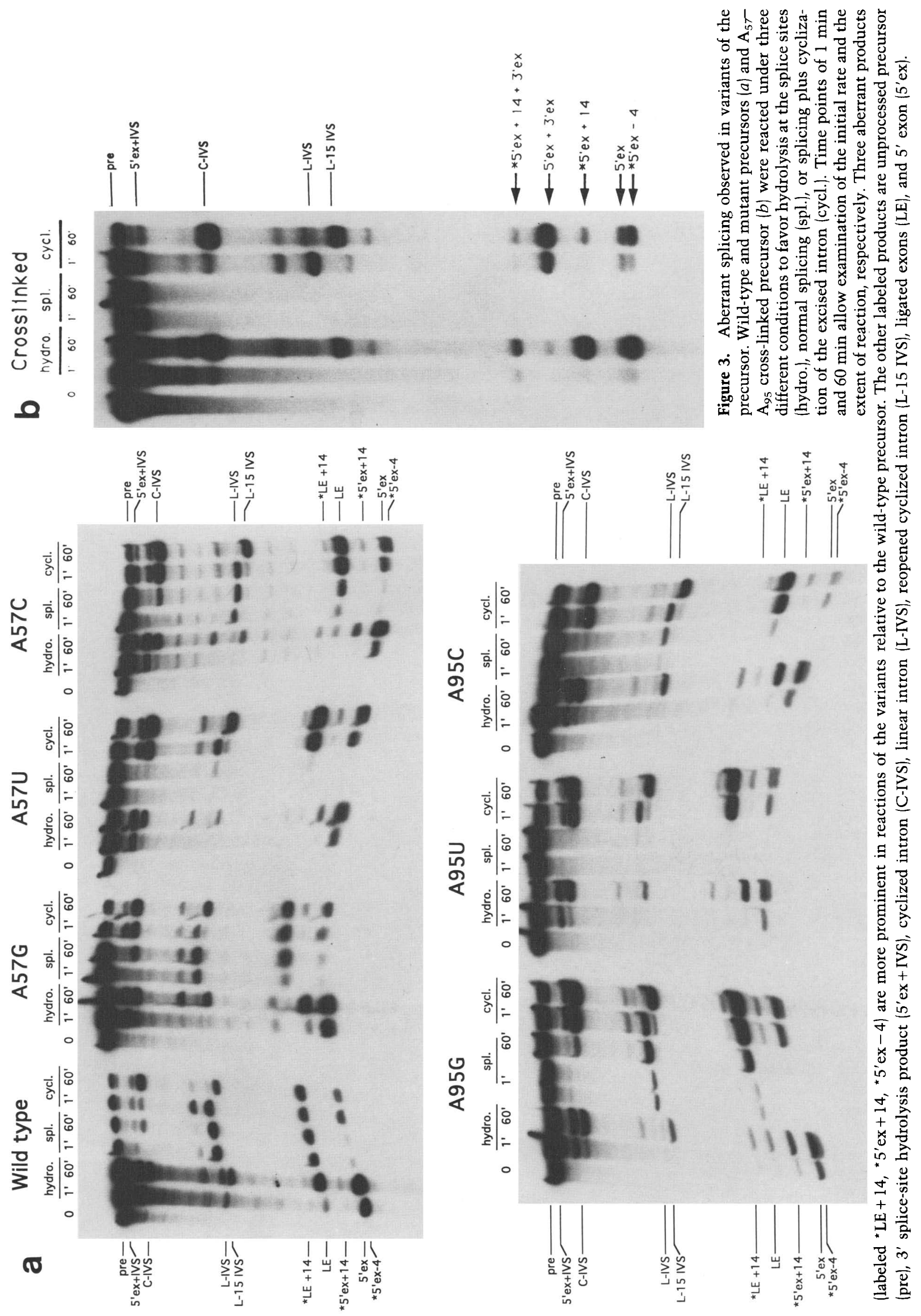




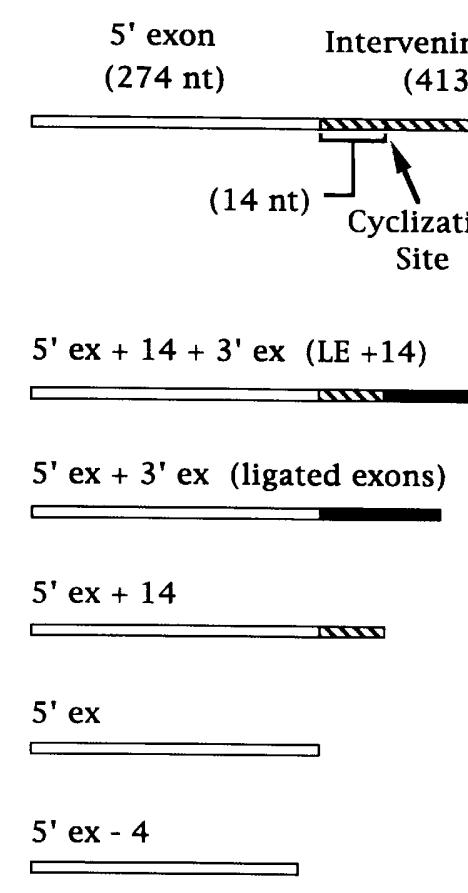

Figure 4. Identities of the aberrant products generated by A57N, A95N, and cross-linked precursors. (Top)A diagram of BGTZ, an unspliced precursor derived from the Tetrahymena rRNA gene comprised of the $5^{\prime}$ exon [open region], the intron (hatched region), and the $3^{\prime}$ exon (solid region). (Below) $5^{\prime}$ Exon (5'ex)-containing products observed following splicing of the mutant and cross-linked precursors.

give a more severe phenotype than mutations of $A_{57}$. This suggests that $A_{95}$ may play a more important role in the folded structure or at least a role that is more basespecific than that of $A_{57}$. Second, mutating $A_{57}$ or $A_{95}$ to a pyrimidine $(\mathrm{U}, \mathrm{C})$ is more detrimental than mutating it to another purine $(G)$. Pyrimidines typically do not contribute as much energetically to stacking interactions as purines (Saenger 1984; Freier et al. 1986). Therefore, this second observation is consistent with $A_{57}$ and $A_{95}$ participating in one or more stacking interactions. $A_{57} G$, which has the weakest phenotype of all the variants, presumably has a structure most similar to that of the wild-type precursor. As mentioned above, this mutant RNA still undergoes cross-linking.

The most severe phenotype occurs when the precursor is cross-linked (Fig. 3b). Following formation of a crosslink, adenines typically lose their planar form because double bonds are converted into single bonds (Gasparro and Fresco 1986; Kumar et al. 1987). The loss of both planar structure and aromaticity in these bases should hamper stacking with other nucleotides and prevent packing of these nucleotides into the rest of the folded structure. In tRNA, the introduction of an UV-inducible cross-link has been observed to measurably alter the tertiary structure (Favre et al. 1971).

The $A_{57} / A_{95}$ interaction promotes reaction at the $5^{\prime}$ splice site

In the various $\mathrm{A} 57 \mathrm{~N}$ and $\mathrm{A} 95 \mathrm{~N}$ mutants and in the cross- linked precursor, only cleavage at the $5^{\prime}$ splice site seems to be impaired. This is best assessed under hydrolysis conditions (Fig. 3), where the initial product of 3 ' splicesite hydrolysis $\left(5^{\prime} \mathrm{ex}+\mathrm{IVS}\right)$ and the subsequent products (C-IVS and $\left.5^{\prime} \mathrm{ex}+14\right)$ are still generated efficiently in reactions that do not depend on cleavage at the $5^{\prime}$ splice site. Also, $5^{\prime}$ splice-site cleavage is impaired more than cleavage at the major cyclization site $\left(5^{\prime} s s+14\right)$, as indicated by the increased ratio of $5^{\prime} \mathrm{ex}+14$ to $5^{\prime}$ exon in the mutants relative to wild type.

In addition, a double mutation known to impair the first step of splicing mimics the phenotype of the A57N, A95N, and cross-linked precursors. At the $5^{\prime}$ splice site is a U - G base pair (Fig. 2), a universal feature of group I introns. In the Tetrahymena intron, replacing this base pair with a Watson-Crick base pair greatly reduces cleavage at the $5^{\prime}$ splice site (Barfod and Cech 1989; Doudna et al. 1989). When the U - G base pair is replaced with a G-C base pair, increased amounts of $5^{\prime} \mathrm{ex}-4$ and 5 'ex +14 are produced (see A test of the two models for 5 'ss -4 cleavage, below). The implication is that 5 'ss +14 and 5 'ss -4 are secondary sites for cleavage in the first step of splicing. In the wild-type precursor, cleavage at the $5^{\prime}$ splice site presumably outcompetes cleavage at $5^{\prime}$ ss +14 and $5^{\prime}$ ss -4 , so only small amounts of $5^{\prime} \mathrm{ex}+14$ and $5^{\prime} \mathrm{ex}-4$ are produced. At least one role of the $A_{57} / A_{95}$ interaction then is to help maintain fidelity in the first step of splicing by promoting cleavage at the 5 ' splice site.

\section{Correlations between 5 'ss +14 and 5'ss -4 cleavages and cyclization}

Cleavage at 5 'ss +14 resembles intron cyclization (Fig. 1 ), which also involves cleavage at 5'ss +14 (Zaug et al. 1983). Cleavage at this site can also occur by hydrolysis (Zaug et al. 1984) or by attack of exogenous guanosine (Tanner and Cech 1987). Therefore, it is not surprising to find that 5 'ss +14 can serve as a default site for cleavage when use of the normal $5^{\prime}$ splice site is somehow impaired. On the other hand, the reason that $5^{\prime} s s-4$ is used as a default site for cleavage is not immediately as clear. The answer lies in a more detailed understanding of cyclization.

Cyclization occurs when a tripyrimidine sequence within the intron $\left(\mathrm{U}_{13} \mathrm{U}_{14} \mathrm{U}_{15}\right.$ or, in a minor reaction, $\mathrm{C}_{17} \mathrm{C}_{18} \mathrm{U}_{19}$ ) base pairs with the IGS (Fig. 5a). Interestingly, this duplex involves the $3^{\prime}$ half of the IGS (Been and Cech 1987) rather than the $5^{\prime}$ half where the cleavage and ligation reactions of splicing take place (Fig. 5a). If disruption of the $A_{57} / A_{95}$ interaction had the general effect of targeting a nucleophile /such as guanosine or water/ to attack sequences base-paired to the $3^{\prime}$ half of the IGS, it would explain not only cleavage at $5^{\prime} s s+14$ but cleavage at 5 'ss -4 as well. According to this model, cleavage at $5^{\prime}$ ss -4 results when the Pl helix remains intact, but P1 is shifted relative to the nucleophile. Instead of attacking at the usual $U_{-1}$ position, the nucleophile attacks at $U_{-5}$, which precedes the $5^{\prime}$ splice site by 4 nucleotides. The $U_{-5}$ nucleotide is involved in the 
first step of splicing

(5'ss)

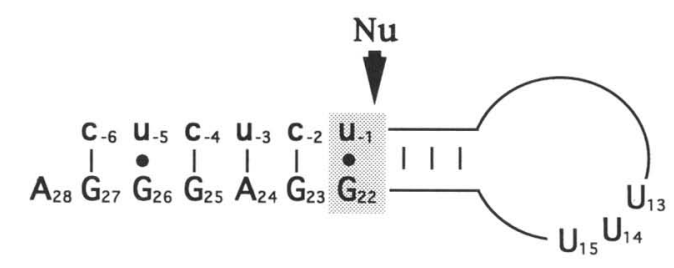

cyclization

(5'ss+14)

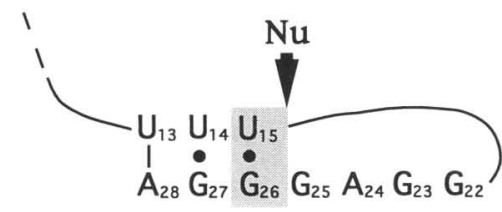

b

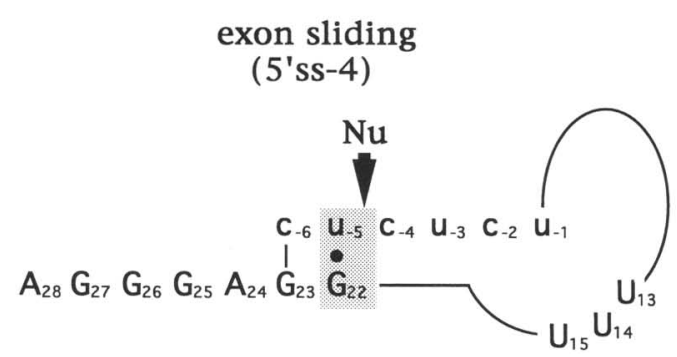

shifted P1

(5'ss-4)

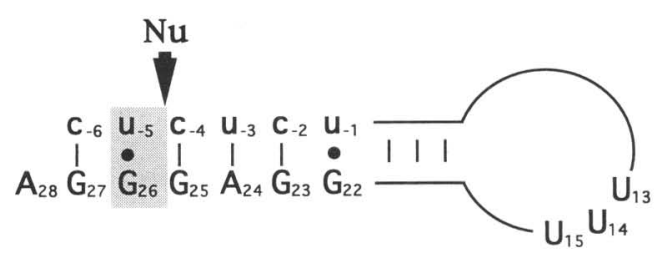

Figure 5. Models for normal and aberrant cleavage near the $5^{\prime}$ splice site $\left(5^{\prime} \mathrm{ss}\right)$. $(a)$ The sequences undergoing cleavage during normal splicing or cyclization by the wild-type Tetrahymena intron (Been and Cech 1986, 1987) shown base-paired with the IGS $\left(\mathrm{G}_{22}-\mathrm{G}_{27}\right)$. $(\mathrm{Nu})$ The cleaving nucleophile, which is either exogenous guanosine (splicing) or $\omega \mathrm{G}$ (cyclization). Shading marks the $U \cdot \mathrm{G}$ base pair that is present at both sites of cleavage. $(b)$ Two models, exon sliding and shifted P1, could account for 5 'ss -4 cleavage in the A57N, A95N, and cross-linked precursor (see text). These models differ from one another in the pattern of base-pairing and the targeting of a nucleophile relative to the IGS during cleavage. Once again, the cleavages occur adjacent to U - G base pairs (shaded).

only other $\mathrm{U} \cdot \mathrm{G}$ base pair in $\mathrm{Pl}$ apart from the normal 5' splice site, and it is the only U base-paired with the $3^{\prime}$ portion of the IGS. Alternative docking of Pl within the active site has explained other cases of inaccurate cleavage (Herschlag 1992). According to this "shifted $\mathrm{Pl}^{\prime \prime}$ model for 5 'ss -4 cleavage, the role of the $A_{57} / A_{95}$ interaction is to position the $\mathrm{P} 1$ helix relative to the site in the intron where the nucleophile is bound (Fig. 5b).

The alternative model for 5 'ss -4 cleavage is "exon sliding". Once again a U - G pair is required for cleavage, but in this case it is composed of $U_{-5}$ and $G_{22}$. To achieve this, the $5^{\prime}$ exon strand of $\mathrm{P} 1$ must slide relative to the IGS, as has been proposed previously (Been and Cech 1987; Zaug and Cech 1986). In this model the IGS remains fixed in position relative to the nucleophile, and only the $U$ that base-pairs with $G_{22}$ changes (Fig. $5 b$ ). Therefore, the role of the $A_{57} / A_{95}$ interaction would be to keep the exon strand of P1 in the correct base-pairing register. One argument against the exon sliding model is that we observe only 5 'ss -4 cleavage and never 5 'ss -2 cleavage. According to this model, there is no obvious reason that a $\mathrm{U}_{-3} \cdot \mathrm{G}_{22}$ pair could not also form and serve as an alternative splice site. There should be more base pairs in the -2 register than the -4 register to stabilize such a duplex.

\section{A test of the two models for 5 'ss -4 cleavage}

A mutational analysis was performed to determine whether 5'ss -4 cleavage behaves according to the shifted P1 or the sliding exon model. According to the shifted P1 model, 5'ss -4 cleavage depends on base-pairing along the $3^{\prime}$ portion of the IGS to permit formation of the $\mathrm{U}_{-5} \cdot \mathrm{G}_{26}$ base pair. If the P1 helix is destabilized in this region, it should disrupt 5 'ss -4 cleavage. However, if the exon sliding model is true, these mutations should not disrupt 5'ss -4 cleavage. Another prediction of the exon sliding model is that mutations in the $5^{\prime}$ portion of the IGS should prevent 5 'ss -4 cleavage because of a destabilization of the $U_{-5} \cdot G_{22}$ base pair.

To examine destabilization in different regions of $\mathrm{P} 1$, mismatches were introduced into the helix through single purine $\rightarrow C$ transversions along the IGS (Fig. 6a). In each of these mutants, the $A_{57} / A_{95}$ structure was disrupted by cross-linking the precursor. The self-processing activity of each cross-linked precursor was then examined under splicing, hydrolysis, and cyclization conditions for formation of normal and aberrant splicing products. The $5^{\prime}$ exon-containing products generated by some of these cross-linked mutant precursors /designated $\mathrm{X}-\mathrm{L} /$ are shown in Figure $6 \mathrm{~b}$. Upon irradiation of 
a

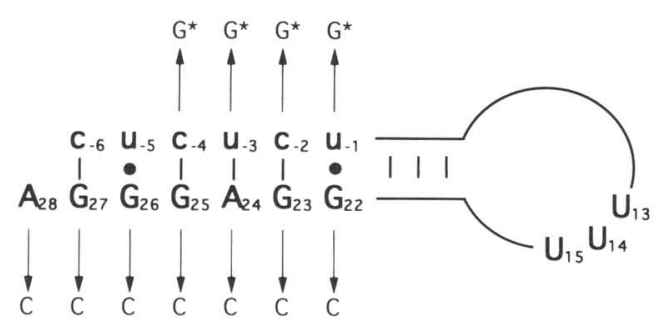

C

$$
A_{28} G_{27} G_{26} G_{25}^{*} A_{24}^{*} G_{23}^{*} G_{22} \quad 5 ' s s-4
$$

$A_{28} G_{27} G_{26} G_{25} A_{24} G_{23} G_{22} \quad 5$ 'ss

$A_{28} G_{27} G_{26} G_{25} A_{24} G_{23} G_{22} \quad 5 ' s s+14$

$A_{28} G_{27} G_{26} G_{25} A_{24} G_{23} G_{22} \quad$ cyclization

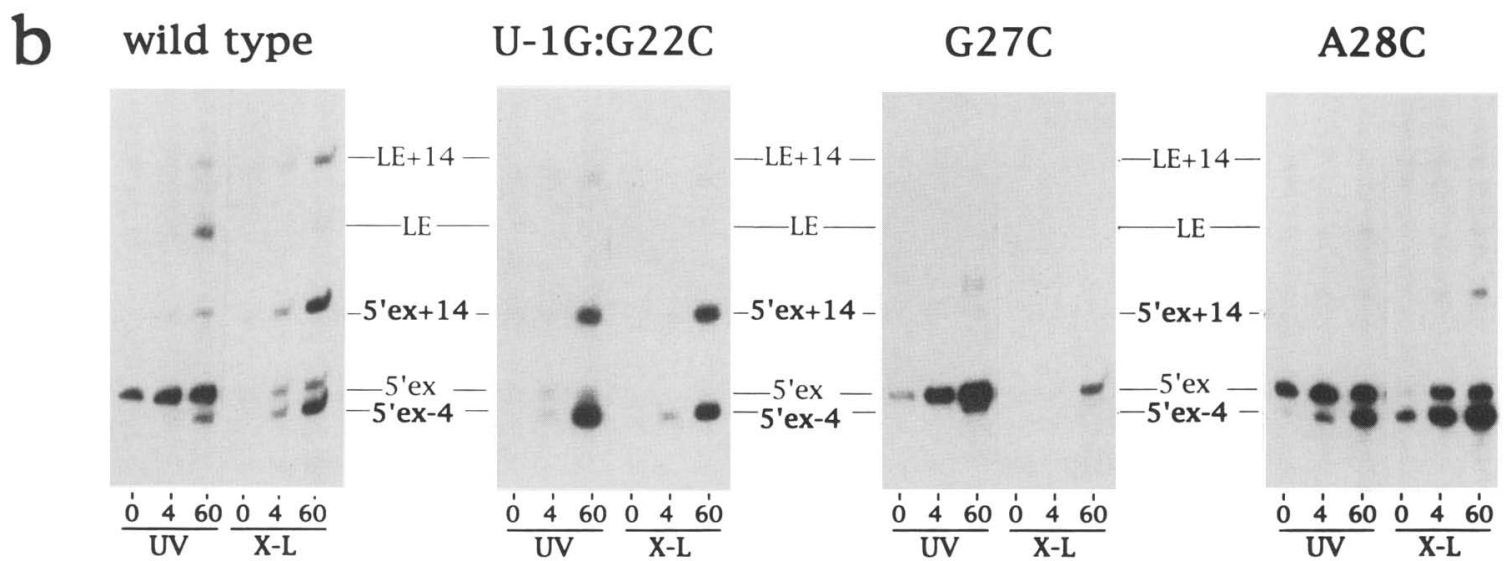

Figure 6. Mutational analysis of P1. (a) Diagram of the P1 helix showing point mutations that were introduced into the Tetrahymena precursor RNA. The asterisks indicate mutations that were examined only in compensatory double mutants that introduced a G-C base pair into P1. (b) Hydrolysis reactions of cross-linked (X-L) and UV-irradiated but uncross-linked (UV) RNA precursors. For each mutant precursor a portion of a denaturing gel is shown displaying those products containing $5^{\prime}$ exon $\left(5^{\prime}\right.$ ex) that were generated during the hydrolysis reaction. Each lane displays an aliquot taken from the reaction mix immediately after heat renaturation of the RNA precursor by snap-cooling (0), or after an additional 4 or $60 \mathrm{~min}$ incubation at $42^{\circ} \mathrm{C}(4$ and 60 , respectively). (c) IGS sequences that proved important in generating the various cleavage and cyclization products. The sites of mutations within the IGS that prevent formation of each product are boxed. Asterisks indicate sites where a single point mutation prevents formation of 5 'ex -4 , but introduction of an alternative G-C base pair at this site does not impair generation of 5'ex-4.

these precursors, a fraction of the molecules remained uncross-linked. This uncross-linked fraction of UV-irradiated precursor (designated as UV in Fig. 6b) was also tested for activity. This was done to rule out the possibility that any phenotypes observed in the cross-linked precursor were attributable to general UV damage rather than the $A_{57}-A_{95}$ cross-link and mutation present.

The mutational analysis revealed sequences of the IGS required for each of four cleavage reactions: $5^{\prime} \mathrm{ss}-4,5^{\prime}$ splice site, 5 'ss +14 , and cyclization (which involves cleavage at $5^{\prime}$ ss +14 by the 3 '-terminal $G$ of the intron). Cyclization was evaluated by the formation of C-IVS RNA (not shown in Fig. 6b; see Fig. 3 for typical data). The required sequences are marked by boxes in Figure $6 \mathrm{c}$. Cleavage at the $5^{\prime}$ splice site only requires sequence identity within the $5^{\prime}$ half of the IGS $\left(\mathrm{G}_{22}\right.$ and $\left.\mathrm{G}_{23}\right)$. The other three cleavage reactions- 5 'ss $-4,5$ 'ss +14 , and cyclization-require that the sequence be preserved in the $3^{\prime}$ half of the IGS $\left(G_{25}\right.$ to $\left.A_{28}\right)$ rather than the 5' half.
In the mutants G22C (data not shown) and U-1G: G22C (Fig. 6b) 5'ss -4 cleavage occurs to generate $5^{\prime} \mathrm{ex}-4$ independent of cross-linking of the precursor. As mentioned before, these mutations eliminate the $\mathrm{U}_{-1} \cdot \mathrm{G}_{22}$ pair at the $5^{\prime}$ splice site, so $5^{\prime} \mathrm{ss}-4$ and 5 'ss +14 become default sites of cleavage. The observation of 5 'ss -4 cleavage in these mutants with or without cross-linking supports the conclusion that the exon sliding model is not valid. Without $\mathrm{G}_{22}$, a $\mathrm{U}_{-5} \cdot \mathrm{G}_{22}$ pair is impossible, and without a $\mathrm{U} \cdot \mathrm{G}_{22}$ pair, $\mathrm{P} 1$ would no longer be able to dock in its normal position in the active site.

Transversions at position $\mathrm{G}_{26}$ or $\mathrm{G}_{27}$ eliminate both cyclization and production of 5 'ex +14 (see G27C, Fig. 6b). However, there are slight differences between these two reactions: The rate of cyclization is affected more severely by alteration of $G_{25}$, whereas 5 'ss +14 cleavage requires that $A_{28}$ be preserved. Because the $G_{25} \rightarrow A_{28}$ region of the IGS was implicated previously in guiding 
various cyclization reactions (Been and Cech 1987), the elimination of 5 'ss +14 cleavage by changes in $G_{26}$ to $A_{28}$ suggests the same sort of alignment is being used.

Cleavage at the $5^{\prime}$ ss -4 site shows a similar requirement for sequences near the $3^{\prime}$ portion of the IGS, as predicted by the shifted $\mathrm{Pl}$ model for cleavage. In this case, changes of nucleotides $G_{23}, A_{24}$, and $G_{25}$ do not prohibit 5 'ss -4 cleavage when they are accompanied by compensatory changes in the exon strand to restore the base-pairing in $\mathrm{Pl}$ (sites indicated by asterisks in Fig. 6c). However, when single transversions are introduced anywhere from $G_{23}$ through $G_{27}, 5$ 'ss -4 cleavage is lost in the cross-linked precursor. This result is different from that observed for the cyclization reaction and 5 'ss +14 cleavage, where transversions can be tolerated at nucleotides $G_{23}$ and $A_{24}$ without maintaining base-pairing in P1. We propose that either the shifted orientation of P1 required for cleavage at 5 'ss -4 requires base pairs beyond the site of cleavage (base pairs that are not required for cyclization), or the introduction of mismatches within Pl distorts the 6-bp duplex enough to prohibit 5 'ss -4 cleavage.

Finally, one other mutant (A28C) gives 5 'ss -4 cleavage even in unirradiated (data not shown) and UV-irradiated but uncross-linked precursors (Fig. $6 \mathrm{~b}$ ). $\mathrm{A}_{28}$ is not actually a nucleotide of the IGS but the first nucleotide of the triadenosine linker $\mathrm{J1} / 2$ that connects $\mathrm{P} 1$ and $\mathrm{P} 2$. This result supports the proposition that $J 1 / 2$, like the $\mathrm{A}_{57} / \mathrm{A}_{95}$ interaction, plays a role in positioning $\mathrm{P} 1$ (Young et al. 1991).

\section{$5^{\prime}$ ss - 4 cleavage depends on sequences near the $3^{\prime}$} splice site

Splicing was examined further in precursors lacking a $3^{\prime}$ exon ( $\omega \mathrm{G}$ transcripts) or lacking both a $3^{\prime}$ exon and 5 nucleotides from the $3^{\prime}$ end of the intron (ScaI transcripts; Fig. 2). These truncated precursors also contained either an $A_{57}$ or $A_{95}$ mutation to promote 5'ss - 4 cleavage. Initially, we assumed that the aberrant splicing phenotype was attributable to effects involving only the first step of splicing so the 3 ' exon could be deleted without changing the phenotype. Instead, deletions from the $3^{\prime}$ end did have effects, and these effects varied according to the sequence removed.

The ScaI transcripts do not generate $5^{\prime} \mathrm{ex}-4$ or 5 'ex +14 products. However, the $\omega \mathrm{G}$ transcripts not only generate $5^{\prime} \mathrm{ex}-4$ and $5^{\prime} \mathrm{ex}+14$ but give a higher yield than that obtained with the full-length precursor (Fig. 7). These results indicate that the $3^{\prime}$ terminal sequence of the Tetrahymena intron is necessary for cleavage at the cryptic sites. It seems likely that $\mathrm{G}_{414}$ serves as the nucleophile for 5 'ss -4 and 5 'ss +14 cleavage, just as it does in cyclization of the intron (Fig. 1).

\section{Discussion}

\section{$A_{57}$ and $A_{95}$ interact to promote accurate splicing}

We conclude that $A_{57}$ and $A_{95}$ are not only close to one another within the folded structure of the Tetrahymena
3' exon $\quad \omega G \quad$ Sca I

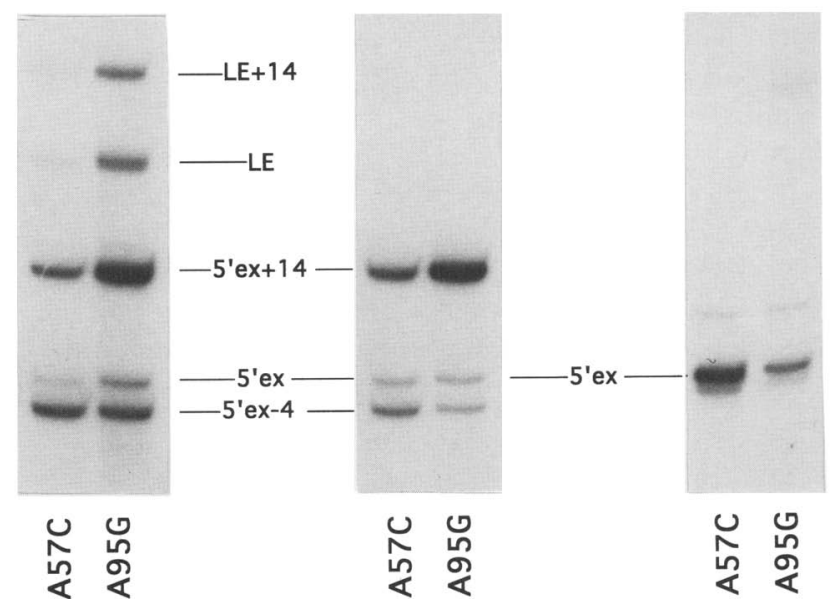

Figure 7. Reaction of precursors differing in their $3^{\prime}$ ends. Six different precursors were taken through a 60 -min self-processing reaction under hydrolysis conditions (see Materials and methods). The autoradiographs display those cleavage products containing the $5^{\prime}$ exon. In each precursor the $\mathrm{A}_{57} / \mathrm{A}_{95}$ interaction is disrupted by either a transversion (A57C) or a transition (A95G). The precursors varied in their 3' termini (see Fig. 2). The longest precursors included a 29-nucleotide exon (3' exon). Next in length were precursors without a $3^{\prime}$ exon but possessing the full intron sequence, including the terminal guanosine nucleotide $\{\omega \mathrm{G}\}$. The shortest precursors lacked both the $3^{\prime}$ exon and the last 5 nucleotides of the intron sequence (ScaI).

intron but actually interact to promote efficient and accurate self-splicing. The proximity of $\mathrm{A}_{57}$ and $\mathrm{A}_{95}$ was revealed previously by their ability to cross-link when subjected to UV irradiation (Downs and Cech 1990). We now conclude that $A_{57}$ and $A_{95}$ interact in a common structure based on the finding that point mutations at either site result in the same phenotype. However, until the reaction is dissected into its elemental steps, we cannot rule out the possibility that these nucleotides act at different points to affect the same steps of the reaction.

For precursors altered at $A_{57}$ or $A_{95}$, conditions that promote splicing $\left(30^{\circ} \mathrm{C}, 3 \mathrm{~mm} \mathrm{MgCl}_{2}\right)$ reduce activity in the first step, $5^{\prime}$ splice-site cleavage. Under conditions that promote splicing and intron cyclization or that promote splice-site hydrolysis $\left(42^{\circ} \mathrm{C}, 10 \mathrm{~mm} \mathrm{MgCl}_{2}\right)$, two alternative sites of cleavage are utilized: 4 nucleotides upstream $\left(5^{\prime}\right.$ ss -4$)$ and 14 nucleotides downstream $\left(5^{\prime} \mathrm{ss}+14\right)$ of the $5^{\prime}$ splice site. The same phenotype is observed when $U_{-1} \cdot G_{22}$, a critical component of $5^{\prime}$ splice-site recognition (Barfod and Cech 1989; Doudna et al. 1989), is replaced with a mismatch or an alternative base pair (Fig. 6b).

Significantly, however, activation of cleavage at position -4 is not simply the consequence of reducing the rate of cleavage at the normal $5^{\prime}$ splice site. Other mutations decrease the rate of reaction without activating cleavage at positions -4 and +14 , including base pair changes and mismatches in P7 (Burke et al. 1986) and in 
P4 (Flor et al. 1989), and mutations near the $3^{\prime}$ splice site that reduce $5^{\prime}$ splice-site activity (Price and Cech 1988). This supports our interpretation that $\mathrm{A}_{57}$ and $\mathrm{A}_{95}$ participate specifically in proper positioning of the $5^{\prime}$ splice site, as do $U_{-1} \cdot G_{22}$ (A. Pyle, T. Chapman, T. Cech, D. Turner, and S. Moran, in prep.; S. Strobel and T. Cech, unpubl.) and J1/2 (Young et al. 1991; Herschlag 1992). Of these, $U_{-1} \cdot G_{22}$ is right at the normal reaction site and $J 1 / 2$ would be expected to be structurally linked to it (Fig. 2). $A_{57} / A_{95}$ is not obviously linked to the $5^{\prime}$ splice site by proximity in sequence or secondary structure, so we propose that it interacts through tertiary structure.

\section{A new explanation for cryptic splice sites}

Explanations have been put forth for cleavage at cryptic $5^{\prime}$ splice sites in nuclear pre-mRNA splicing (Zhuang and Weiner 1986; Seraphin et al. 1988; Siliciano and Guthrie 1988; Newman and Norman 1992; Lesser and Guthrie 1993) and self-splicing in group I (Perea and Jacq 1985; Chandry and Belfort 1987; Price et al. 1987; Winter et al. 1992) and group II introns (Muller et al. 1988; Jacquier and Jacquesson-Breuleux 1991). In these cases, a guide sequence provided by an snRNA (U1, U5, or U6) or by a self-splicing intron is proposed to base-pair with sequences flanking the cryptic 5 ' splice site.

We present a different sort of explanation for our results. In a wild-type precursor, $A_{57}$ and $A_{95}$ cooperate in positioning the $5^{\prime}$ splice-site helix relative to a bound nucleophile. When the $A_{57} / A_{95}$ interaction is disrupted in $\mathrm{A} 57 \mathrm{~N}$ and $\mathrm{A} 95 \mathrm{~N}$ mutants and in cross-linked precursor, the $5^{\prime}$ splice site and the bound nucleophile no longer share a proper alignment for attack much of the time. This accounts for the observation that 5 ' splicesite cleavage is impaired in these variants. Furthermore, when the $A_{57} / A_{95}$ interaction is disrupted, P1 moves to new positions, the other $U \cdot G$ pair within $P 1$ is aligned with the bound nucleophile, and alternative cleavage along P1 results. This would be the situation in $5^{\prime}$ ss -4 cleavage. Our results do not provide a detailed explanation for the role of $U \cdot G$. For instance, the position of the Pl helix may be determined in part by recognition of a specific functional group on the $U \cdot G$ pair (S. Strobel and T. Cech, unpubl.), or the P1 helix may be bound in multiple positions (Herschlag 1992) with reaction being greatly enhanced by a U - G pair, or both. In any case, the same $U \cdot G$ pair is chosen even when other base pairs in $\mathrm{Pl}$ are altered, suggesting that it is the $\mathrm{U} \cdot \mathrm{G}$ pair itself that is important for recognition, reaction, or both.

Demonstration that $\mathrm{Pl}$ can dock in different registers within the catalytic core was provided earlier by Herschlag (1992), who studied the promiscuous cleavage at positions $-1,-2$, and -3 observed in $\mathrm{J1} / 2$ mutants (Young et al. 1991) of an enzymatic form of the Tetrahymena ribozyme. The lack of significant cleavage at position -4 in Herschlag's system contrasts with the preponderance of infidelity at -4 described herein. The substitution of a $\mathrm{C}$ for $\mathrm{U}_{-5}$ in the enzymatic system, which would give a standard C-G base pair in P1, presumably contributes to this difference, although it is also possible that the different mutations give distinct patterns of infidelity because they perturb the structure differently.

\section{Cryptic cleavages appear to be attributable to cyclization reactions}

There are several correlations between cleavage at either the $5^{\prime} s s-4$ or the 5 'ss +14 site and the third step of processing of the Tetrahymena pre-rRNA, intron cyclization. The same changes in reaction conditions (higher temperature and $\mathrm{MgCl}_{2}$ concentration) that promote cyclization also promote the aberrant cleavage reactions of the mutants. Cleavage depends on the $3^{\prime}$ portion of the IGS, suggesting a displacement of the IGS relative to the catalytic machinery of the core. Aberrant cleavage products, $5^{\prime} \mathrm{ex}-4$ and $5^{\prime} \mathrm{ex}+14$, are generated in even higher yield in the absence of guanosine, suggesting that the nucleophile is something other than guanosine from solution.

In fact 5 'ss +14 is the major cyclizaton site in the Tetrahymena intron (Zaug et al. 1983). In 5 'ss +14 cleavage the precursor presumably assumes an arrangement very similar to that of the excised intron during cyclization, as a default reaction. However, the two reactions are not identical, as 5 'ss +14 cleavage makes slightly different demands on the sequence identity of the IGS than those required for cyclization (Fig. 6c).

Finally, the results of deleting sequence from the $3^{\prime}$ end of the precursor can be explained if 5 'ss -4 and 5 'ss +14 cleavages are the consequence of cyclization reactions. When the $3^{\prime}$ exon and 5 nucleotides at the extreme $3^{\prime}$ end of the intron are removed from an A57C or A95G precursor (ScaI transcripts), 5'ss -4 and $5^{\prime}$ ss +14 cleavage do not occur. Meanwhile removal of the 3' exon alone does not prevent the aberrant cleavage reactions. The 5-nucleotide sequence required for these cleavage reactions includes $G_{414}$, the nucleotide that is required as the nucleophile during cyclization. During normal processing of the Tetrahymena intron, cyclization cannot occur until cleavage occurs at the $3^{\prime}$ splice site (e.g., the second step of splicing). This is because the $3^{\prime} \mathrm{OH}$ group of $\mathrm{G}_{414}$ must be freed from its phosphodiester linkage to carry out the nucleophilic attack. In the $\omega \mathrm{G}$ transcripts of $\mathrm{A} 57 \mathrm{C}$ and $\mathrm{A} 95 \mathrm{G}$, the $3^{\prime}$ exon has been removed and $\mathrm{G}_{414}$ has been retained, now with a free $3^{\prime} \mathrm{OH}$, so 5 'ss -4 and 5 'ss +14 cleavages can occur.

In the $\mathrm{A}_{57}$ and $\mathrm{A}_{95}$ mutant and cross-linked Tetrahymena precursors, the first step of splicing is impaired, leaving the $3^{\prime}$ splice site available for site-specific hydrolysis (Inoue et al. 1986). This hydrolysis reaction is likely the means for liberating the $3^{\prime}$ hydroxyl group of $\mathrm{G}_{414}$ and allowing it to act as the nucleophile in cyclization. In 5 'ss +14 cleavage a cyclization reaction essentially identical to the third step of processing occurs prematurely. Cleavage at the 5'ss -4 site utilizes the P1 helix, an element of the first step of splicing, in a cyclization reaction. Thus, disrupting the $\mathrm{A}_{57} / \mathrm{A}_{95}$ interaction promotes reaction pathways that bypass the first step of splicing. 
In a limited number of molecules cleavage occurs at the cyclization site $\left(5^{\prime}\right.$ ss +14$)$, and the resulting $5^{\prime} \mathrm{ex}+14$ product can then proceed through the second step of splicing and become ligated to the $3^{\prime}$ exon to give $\mathrm{LE}+14$. It is likely that $\mathrm{LE}+14$ results from $5^{\prime} \mathrm{ex}+14$ reacting with a second precursor RNA in trans, because (1) the $3^{\prime}$ exon is presumably removed from the precursor by hydrolysis as a prerequisite to cyclization and is therefore no longer available for ligation, and (2) cyclization at the 5'ss +14 site will sever the IGS from the remainder of the intron and render the intron incapable of executing the ligation step. A second precursor for one of its processed forms/ must provide the catalytic machinery, including an IGS, for ligation. Likewise, this second molecule may provide the $3^{\prime}$ exon and intact 3 ' splice site for performing a ligation reaction analogous to the second step of splicing.

It is now thought that spliceosome-mediated splicing (Guthrie 1991), as well as group I self-splicing, will require conformational changes between steps of processing. In the processing of the Tetrahymena intron, a change in conformation is expected between the first and second steps (Inoue et al. 1986; Michel and Westhof 1990 ) and as a prerequisite for the third step (Been and Cech 1987). An intriguing possibility is that the $A_{57} / A_{95}$ interaction is disrupted or altered in the conformational switch from splicing to cyclization. There is no evidence that the $\mathrm{A}_{57} / \mathrm{A}_{95}$ interaction is necessary for cyclization. When the linear intron is cross-linked it can still undergo cyclization (W. Downs and T. Cech, unpubl.). The method of aligning the IGS duplex relative to the nucleophile-binding site must therefore be different in cyclization than in the first step of splicing.

\section{A structural model for positioning of $P 1$ by $A_{57} / A_{95}$}

Previously, we presented a model for the arrangement of P1, P2, P2.1, P3, and P7 within the folded Tetrahymena intron based on the $A_{57}-A_{95}$ cross-link and earlier chemical probing studies (Downs and Cech 1990). Accordingly, P1 and two coaxially stacked pairs of helices, P2/ $\mathrm{P} 2.1$ and $\mathrm{P} 3 / \mathrm{P} 7$, are held by tertiary interactions in an arrangement with the nucleophile-binding site in P7 juxtaposed to the $5^{\prime}$ splice site (Fig. 8, square in P1). The $\mathrm{A}_{57} / \mathrm{A}_{95}$ interaction presumably takes part in positioning $P 1$ relative to $P 7$, one of a number of interactions that contribute to this function (Barfod and Cech 1989; Doudna et al. 1989; Young et al. 1991; Pyle et al. 1992; Strobel and Cech 1993, 1994|. Displacement of P1 upward relative to $\mathrm{P} 7$ (Fig. 8, middle) could account for the loss of cleavage at the $5^{\prime}$ splice site and the occurrence of cleavage closer to the base of the P1 stem (e.g., 5'ss -4). But for the stacking of $A_{57}$ and $A_{95}$ to position P1 and P7, there must be a bridge of structural interactions that leads to each.

$A_{95}$ is highly conserved among group I introns $(86 \%)$, and it exists at one end of P3. This is the edge of the catalytic core, which contains secondary structure elements and nucleotides conserved among group I introns. $\mathrm{P} 3$ packs tightly against the $\mathrm{P} 2 / 2.1$ coaxial helix as revealed by modeling of the $A_{57}-A_{95}$ cross-link and solvent accessibility patterns (Inoue and Cech 1985; Latham and Cech 1989; Downs and Cech 1990) Therefore, it is reasonable that the $\mathrm{A}_{57} / \mathrm{A}_{95}$ interaction influences the position of P3. P7 stacks upon P3 and contains at least a portion of the nucleophile binding site (Michel et al. 1989a). Therefore, a pathway can be envisaged for the
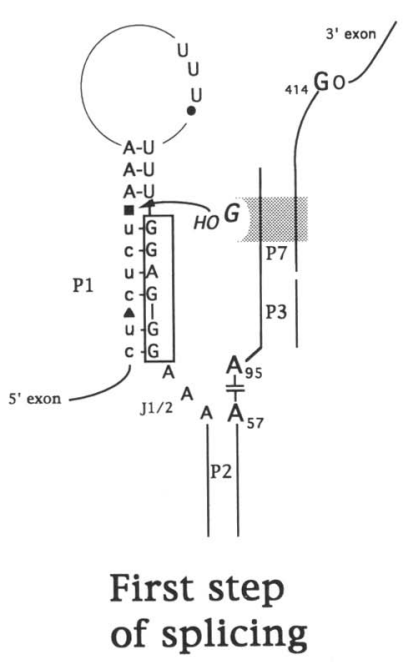
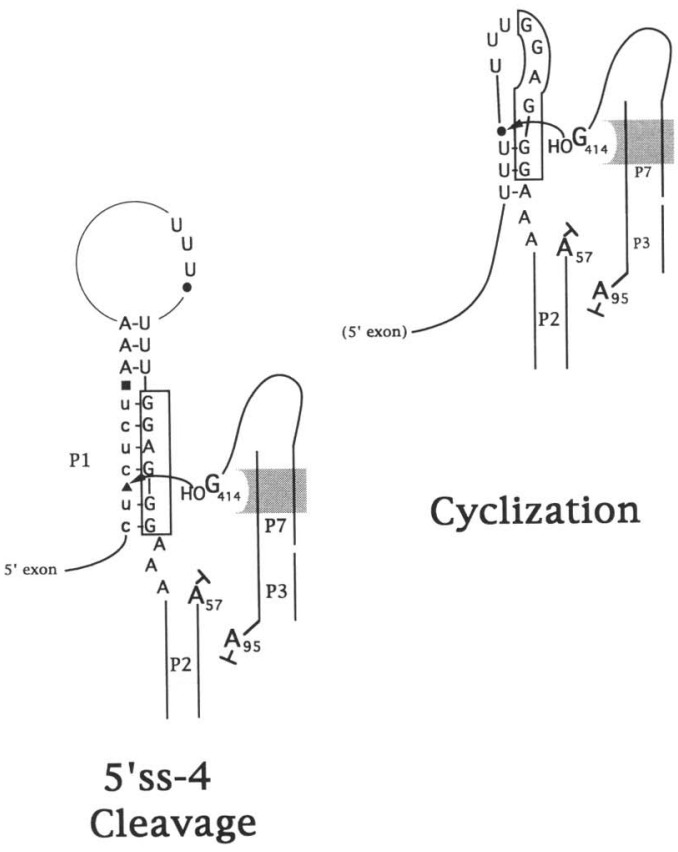

Figure 8. A model for the positioning of the IGS and P7 during self-processing. Three different structural arrangements are proposed to occur during cleavage at the $5^{\prime}$ splice site $(\boldsymbol{\square})$, the 5 'ss -4 site $(\boldsymbol{\Delta})$, and the major cyclization site (O). In each case, cleavage depends on alignment of a guanosine bound at the nucleophile-binding site (the shaded region of $\mathrm{P} 7$ ) relative to the cleavage site, which is base-paired to the IGS (the boxed sequence in each diagram). A tertiary interaction involving $\mathrm{A}_{57}$ and $\mathrm{A}_{95}$ is necessary only in the first step of splicing, to position the P1 helix. Arrows indicate attack by the guanosine bound in the nucleophile-binding site. 
$A_{57} / A_{95}$ interaction to influence the position of the nucleophile-binding site via $\mathrm{P} 3$.

The influence of the $A_{57} / A_{95}$ interaction on the position of $\mathrm{P} 1$ could be mediated through the structural elements $\mathrm{P} 2$ and $J 1 / 2$. The $\mathrm{A}_{57}$ and $\mathrm{A}_{95}$ stacking arrangement is predicted to lie at the heart of the $\mathrm{P} 2 / 2.1$ coaxial helix so this interaction could influence the position of $5^{\prime}$ sequences through P2. Between P2 and P1 there exists a triadenosine linker, $\mathrm{J} 1 / 2$ (see Fig. 2). If this linker possesses a defined structure it could be utilized by the $A_{57} /$ $\mathrm{A}_{95}$ interaction to position P1. Several lines of evidence indicate that this linker does have a structure or participates in additional interactions that position Pl. Altering the length of $J 1 / 2$ in an RNA enzyme form of the Tetrahymena intron resulted in lower affinity for binding of substrate (a $5^{\prime}$ exon analog) (Young et al. 1991) as well as binding of the substrate in the wrong register within the active site (Herschlag 1992). There is also a requirement for the $5^{\prime}$ splice site to be a specific distance from the bottom of P1 (Doudna et al. 1989), which suggests that there is some structural element below the 5' splice site that positions it in the active site. J1/2 may have a rigid structure or participate in specific interactions permitting it to push $\mathrm{P} 1$ into its proper place within the catalytic core of the Tetrahymena intron. $\mathrm{Jl} / 2$ has the sequence $\mathrm{AAA}$, and at low temperatures and neutral $\mathrm{pH}$ poly(rA) can adopt a single-stranded rod-like structure (Stannard and Felsenfeld 1975). A final piece of evidence in support of this model is that the precursor mutant $\mathrm{A} 28 \mathrm{C}$ generates $5^{\prime} \mathrm{ex}-4$ product even when it is not cross-linked (Fig. 6b). $A_{28}$ is the first nucleotide of the $J 1 / 2$ linker. Presumably introducing a pyrimidine at this position reduces the ability of $\mathrm{P} 1$ to stack on the $\mathrm{Jl} / 2$ linker or disrupts a tertiary structure involving the linker.

The picture that emerges is one of structural connectivity from $\mathrm{P} 1$ to $\mathrm{P} 7$, going from $\mathrm{A}_{57}$ through $\mathrm{P} 2$ and J1/2 to $P 1$ in one direction and from $A_{95}$ through the P3 helix to $\mathrm{P} 7$ in the other direction. The $\mathrm{A}_{57} / \mathrm{A}_{95}$ interaction lies within this structural path and occurs at a point where the ends of three helices, P2, P2.1, and P3, converge. Therefore, disrupting this interaction would be expected to break the structural connectivity between $\mathrm{P} 1$ and $\mathrm{P} 7$ by destabilizing the coaxial stacking of $\mathrm{P} 2$ and $\mathrm{P} 2.1$, the packing between $\mathrm{P} 2 / 2.1$ and $\mathrm{P} 3$, or both. This model suggests that there could be other sites where mutations could affect fidelity in splicing, but $\mathrm{A} 57 \mathrm{~N}$ and $\mathrm{A} 95 \mathrm{~N}$ are the first mutations outside of $\mathrm{Pl}$ and the adjacent joining region, $\mathrm{J} 1 / 2$, found to do so.

\section{Generality}

In all cases of RNA-mediated splicing, the $5^{\prime}$ splice site is chosen in part by formation of an RNA duplex: the P1 duplex in group I self-splicing, the EBS1 - IBS1 duplex in group II self-splicing, and pairing of sequences near the $5^{\prime}$ splice site first with U1 snRNA and later with U5 and U6 snRNAs in the case of nuclear mRNA splicing (Green 1991; Guthrie 1991; Wassarman and Steitz 1992; Kandels-Lewis and Séraphin 1993; Lesser and Guthrie
1993; Sontheimer and Steitz 1993). In all cases, a second RNA duplex holds the nucleophile that will attack the $5^{\prime}$ splice site (Michel et al. 1989a,b; Guthrie 1991). Thus, precise positioning of the $5^{\prime}$ splice-site duplex relative to the nucleophile-containing duplex is likely to be a common requirement for all of these splicing reactions. In this paper we have described a tertiary interaction that contributes to this positioning in the case of a group I intron. Extrapolating from the group I introns, we predict that RNA elements will be found in snRNAs /such as U5 or U6) and in group II introns that increase fidelity of splicing by promoting the correct positioning of helices. Disruption of such interactions may explain the phenotypes of mutations at positions $\mathrm{G}_{50}$ and $\mathrm{G}_{52}$ in yeast $\mathrm{U} 6$ snRNA described by Lesser and Guthrie (1993) and the aberrant splicing caused by a 4-base mutation in a nearby region of U6 snRNA in a nematode reported by Yu et al. (1993).

\section{Materials and methods}

Templates

Unprocessed pre-rRNA containing the Tetrahymena intron was transcribed from the pBGTZ construct (provided by Daniel Celander, University of Illinois, Urbana). This plasmid was made by inserting a Scal fragment from pBGST7 (Been and Cech 1986) into a fragment of the pTZ18U vector. This template yields the same RNA precursors as the pBGST7 plasmid described previously (Been and Cech 1986). However, pBGTZ is also a phagemid construct and was used to make the U-1G:G22C and G22C constructs with the Muta-Gene kit (Bio-Rad). Construction of templates that introduce other mutations into $\mathrm{Pl}$ of the Tetrahymena precursor have been described previously (Been et al. 1986, 1987). Prior to use as a template, each plasmid was digested to completion with HindIII to generate the unspliced precursor or with $S c a$ I to generate the truncated template.

\section{Preparation of RNA}

RNA was transcribed acccording to a procedure described by Zaug et al. (1988), with the following exceptions. The $10 \times$ transcription buffer was composed of $200 \mathrm{mM}$ Tris- $\mathrm{HCl}$ (pH 7.5), 75 $\mathrm{mm} \mathrm{MgCl}_{2}, 25 \mathrm{~mm} \mathrm{DTT}$, and $10 \mathrm{~mm}$ spermidine. A l-ml transcription reaction contained $100 \mu l$ of $10 \times$ transcription buffer, $100 \mu$ l of nucleotide $\mathrm{mix}$ (10 mM each GTP, ATP, UTP, CTP), 5-10 $\mu \mathrm{g}$ of linearized template (e.g., pBGTZ/HindIII, pBGTZ/ ScaI), and 1000-2000 units of T7 RNA polymerase. To generate a uniformly labeled transcript, $\left[\alpha-{ }^{32} \mathrm{P}\right]$ ATP $(600 \mathrm{Ci} / \mathrm{mmole}$, New England Nuclear) was included in the transcription reaction and the ATP concentration was reduced to $0.25 \mathrm{~mm}$.

The RNA was precipitated in $0.25 \mathrm{M} \mathrm{NaCl}$ plus three volumes of absolute ethanol, and separated by size by electrophoresis in a denaturing gel containing $8 \mathrm{~m}$ urea. The gel slices were frozen on dry ice, crushed using a sterile, silanized glass pestle, and soaked overnight at $4^{\circ} \mathrm{C}$ in $0.25 \mathrm{M} \mathrm{NaCl}, 10 \mathrm{~mm}$ Tris- $\mathrm{HCl} / \mathrm{pH}$ 7.5), and 1-5 mM EDTA to elute the RNA. The RNA was precipitated with 2.5-3 volumes of absolute ethanol, washed one to two times with $70 \%$ ethanol, dried under vacuum, and resuspended in $10 \mathrm{~mm}$ Tris- $\mathrm{HCl}(\mathrm{pH} 7.5)$ and $1 \mathrm{mM}$ EDTA or in doubly distilled, deionized water.

Recovered precursor RNA was folded into its active conformation prior to reaction or cross-linking by a method of heat renaturation. Accordingly, the RNA was first denatured by 
heating in deionized water for $1-3 \mathrm{~min}$ at $96^{\circ} \mathrm{C}$. One-tenth volume of the appropriate reaction buffer was injected into the IVS solution to introduce the desired concentration of cations. Immediately thereafter, the solution was placed on ice.

\section{Generation of cross-linked and uncross-linked precursor}

Heat-renatured RNA was irradiated at a concentration of 0.2 $\mathrm{mg} / \mathrm{ml}$ or less as droplets $(10-50 \mu \mathrm{l})$ on plastic wrap over ice water. A UVG-11 mineral lamp (UVP Inc.) served as a UV radiation source $\left(\lambda_{\max }=254 \mathrm{~nm}\right)$ and was mounted $5-10 \mathrm{~cm}$ above the samples. An extent of irradiation was chosen that converts approximately half of the precursor into $\mathrm{A}_{57}-\mathrm{A}_{95}$ cross-linked material. The UV-irradiated precursor was ethanol precipitated and subjected to electrophoresis on a denaturing gel $16 \%$ or greater polyacrylamide $/ 7 \mathrm{M}$ urea) to separate the cross-linked and uncross-linked fractions.

\section{Generation of $\omega G$ transcripts}

Full-length transcript (e.g., pBGTZ/HindIII template) was heatrenatured resulting in a final solution of $0.25 \mu \mathrm{M}$ precursor, 50 $\mathrm{mm}$ Tris- $\mathrm{HCl}$ (7.5), $5 \mathrm{~mm} \mathrm{MgCl}$, and $100 \mathrm{~mm} \mathrm{NaCl}$. The RNA oligonucleotide CCCUCU was added to a final concentration of $0.25 \mu \mathrm{M}$ as a reactant to generate $3^{\prime}$ splice site cleavage, and reaction proceeded for $30 \mathrm{~min}$ at $30^{\circ} \mathrm{C}$. An equal volume of $10 \mathrm{M}$ urea/50 mM EDTA was added to stop the reaction. The resulting $\omega \mathrm{G}$ product was recovered from a denaturing polyacrylamide gel as described above in Preparation of RNA.

\section{Self-splicing reactions}

Three different solution conditions and temperatures were used to promote different reactions:

1. Splicing: $200 \mu \mathrm{M}$ guanosine, $50 \mathrm{~mm}$ Tris- $\mathrm{HCl}$ (7.5), $3 \mathrm{~mm}$ $\mathrm{MgCl}_{2}$, and $100 \mathrm{mM} \mathrm{NaCl}$ at $30^{\circ} \mathrm{C}$.

2. Hydrolysis: $50 \mathrm{~mm}$ Tris- $\mathrm{HCl}(7.5), 10 \mathrm{mM} \mathrm{MgCl}_{2}$, and $100 \mathrm{mM}$ $\mathrm{NaCl}$ at $42^{\circ} \mathrm{C}$.

3. Cyclization: $200 \mu \mathrm{M}$ guanosine, $50 \mathrm{~mm}$ Tris- $\mathrm{HCl}$ (7.5), $10 \mathrm{~mm}$ $\mathrm{MgCl}_{2}$, and $100 \mathrm{mM} \mathrm{NaCl}$ at $42^{\circ} \mathrm{C}$.

In each case the RNA was renatured in the appropriate solution and kept on ice. Hydrolysis reactions were initiated by transfer to a $42^{\circ} \mathrm{C}$ water bath. To initiate the splicing or cyclization reactions, the renatured RNA was incubated at the proper reaction temperature $\left(30^{\circ} \mathrm{C}\right.$ or $\left.42^{\circ} \mathrm{C}\right)$ for $15 \mathrm{sec}$ as a $100 \mu \mathrm{l}$ volume, and guanosine was added to a final concentration of 200 $\mu \mathrm{M}$. All reactions were stopped by combining the reaction or an aliquot of the reaction with a $50-100 \%$ volume of stop solution: $10 \mathrm{~m}$ urea, $50 \mathrm{~mm}$ EDTA, $10 \mathrm{~mm}$ Tris- $\mathrm{HCl}(\mathrm{pH} 8.0), 0.01 \% \mathrm{xy}-$ lene cyanole, $0.01 \%$ bromophenol blue. The samples were suitable for loading on a denaturing polyacrylamide gel once combined with the stop solution.

\section{Sequencing of RNA products}

For $3^{\prime}$-end labeling of the RNA cleavage products, $5^{\prime}-\left[{ }^{32} \mathrm{P}\right] \mathrm{pCp}$ (New England Nuclear) was ligated to the $3^{\prime}$ end of the RNA as described by England and Uhlenbeck (1978). After labeling, the RNA was purified by electrophoresis on a $7 \mathrm{M}$ urea denaturing gel. The desired band was visualized by autoradiography, cut from the gel, frozen, and crushed; the fragments were soaked overnight in $0.25 \mathrm{M} \mathrm{NaCl}, 10 \mathrm{~mm}$ Tris- $\mathrm{HCl}$ (pH 7.5), and $5 \mathrm{~mm}$ EDTA, and the labeled RNA was recovered by ethanol precipitation. Enzymatic sequencing and partial alkaline hydrolysis were performed on the end-labeled RNA according to the methods of Donis-Keller et al. (1977). Some variations were made in the procedure: 0.01 units of RNases T1 or U2 (Sankyo) or 1 unit of PhyM (Bethesda Research Laboratories) was incubated in a $5-\mu \mathrm{l}$ reaction mixture containing $0.2 \mathrm{mg} / \mathrm{ml}$ of tRNA for $15 \mathrm{~min}$ at $50^{\circ} \mathrm{C}$. Sequencing by primer extension was performed by a procedure described previously (Zaug et al. 1984).

\section{Acknowledgments}

This research was supported by a grant from the National Institutes of Health (GM28039). T.R.C. is an Investigator of the Howard Hughes Medical Institute and an American Cancer Society Professor.

The publication costs of this article were defrayed in part by payment of page charges. This article must therefore be hereby marked "advertisement" in accordance with 18 USC section 1734 solely to indicate this fact.

\section{References}

Barfod, E.T. and T.R. Cech. 1989. The conserved U-G pair in the $5^{\prime}$ splice site duplex of a group I intron is required in the first but not the second step of self-splicing. Mol. Cell. Biol. 9: 3657-3666.

Been, M.D., E.T. Barfod, J.M. Burke, J.V. Price, N.K. Tanner, A.J. Zaug, and T.R. Cech. 1987. Structures involved in Tetrahymena rRNA self-splicing and RNA enzyme activity. Cold Spring Harbor Symp. Quant. Biol. 52: 147-157.

Been, M.D. and T.R. Cech. 1986. One binding site determines sequence specificity of Tetrahymena pre-rRNA self-splicing, trans-splicing, and RNA enzyme activity. Cell 47: 207-216.

- 1987. Selection of circularization sites in a group I IVS RNA requires multiple alignments of an internal templatelike sequence. Cell 50: 951-961.

Burke, J.M., K.D. Irvine, K.J. Kaneko, B.J. Kerker, A.B. Oettgen, W.M. Tierney, C.L. Williamson, A.J. Zaug, and T.R. Cech. 1986. Role of conserved sequence elements $9 \mathrm{~L}$ and 2 in selfsplicing of the Tetrahymena ribosomal RNA precursor. Cell 45: $167-176$.

Cech, T.R. 1990. Self-splicing of group I introns. Annu. Rev. Biochem. 59: 543-568.

Cech, T.R. and B.L. Bass. 1986. Biological catalysis by RNA. Annu. Rev. Biochem. 55: 599-629.

Cech, T.R., A.J. Zaug, and P.J. Grabowski. 1981. In vitro splicing of the ribosomal RNA precursor of Tetrahymena: Involvement of a guanosine nucleotide in the excision of the intervening sequence. Cell 27: 487-496.

Chandry, P.S. and M. Belfort. 1987. Activation of a cryptic $5^{\prime}$ splice site in the upstream exon of the phage T4 td transcript: Exon context, missplicing, and mRNA deletion in a fidelity mutant. Genes \& Dev. 1: 1028-1037.

Davies, R.W., R.B. Waring, J.A. Ray, T.A. Brown, and C. Scazzocchio. 1982. Making ends meet: A model for RNA splicing in fungal mitochondria. Nature 300: 719-724.

Donis-Keller, H., A.M. Maxam, and W. Gilbert. 1977. Mapping adenines, quanines, and pyrimidines in RNA. Nucleic Acids Res. 4: 2527-2538.

Doudna, J.A., B.P. Cormack, and J.W. Szostak. 1989. RNA structure, not sequence, determines the $5^{\prime}$ splice-site specificity of a group I intron. Proc. Natl. Acad. Sci. 86: 7402-7406. 
Downs, W.D. 1993. "The folded structure of group I RNA enzymes as revealed by ultraviolet-inducible cross-links." Ph.D. Thesis, University of Colorado, Boulder.

Downs, W.D. and T.R. Cech. 1990. An ultraviolet-inducible adenosine-adenosine cross-link reflects the catalytic structure of the Tetrahymena ribozyme. Biochemistry 29: 5605-5613.

England, T.E. and O.C. Uhlenbeck. 1978. 3'-Terminal labelling of RNA with T4 RNA ligase. Nature 275: 560-561.

Favre, A., A.M. Michelson, and M. Yaniv. 1971. Photochemistry of 4-thiouridine in Escherichia coli transfer RNA. I. Mol. Biol. 58: 367-379.

Flor, P.J., J.B. Flanegan, and T.R. Cech. 1989. A conserved base pair within helix $\mathrm{P} 4$ of the Tetrahymena ribozyme helps to form the tertiary structure required for self-splicing. $E M B O$ I. 8: 3391-3399.

Freier, S.M., N. Sugimoto, A. Sinclair, D. Alkema, T. Neilson, R. Kierzek, M.H. Caruthers, and D.H. Turner. 1986. Stability of XGCGCp, GCGCYp, and XGCGCYp helixes: An empirical estimate of the energetics of hydrogen bonds in nucleic acids. Biochemistry 25: 3214-3219.

Gasparro, F.P. and J.R. Fresco. 1986. Ultraviolet-induced 8,8adenine dehydrodimers in oligo- and polynucleotides. $\mathrm{Nu}$ cleic Acids Res. 14: 4239-4251.

Green, M.R. 1991. Biochemical mechanisms of constitutive and regulated pre-mRNA splicing. Annu. Rev. Cell Biol. 7: 559599.

Guthrie, C. 1991. Messenger RNA splicing in yeast: Clues to why the spliceosome is a ribonucleoprotein. Science 253: 157-163.

Herschlag, D. 1992. Evidence for processivity and two-step binding of the RNA substrate from studies of $J 1 / 2$ mutants of the Tetrahymena ribozyme. Biochemistry 31: 1386-1398.

Inoue, T. and T.R. Cech. 1985. Secondary structure of the circular form of the Tetrahymena rRNA intervening sequence: A technique for RNA structure analysis using chemical probes and reverse transcriptase. Proc. Natl. Acad. Sci. 82: 648-652.

Inoue, T., F.X. Sullivan, and T.R. Cech. 1986. New reactions of the ribosomal RNA precursor of Tetrahymena and the mechanism of self-splicing. I. Mol. Biol. 189: 143-165.

Jacquier, A. and N. Jacquesson-Breuleux. 1991. Splice site selection and role of the lariat in a group II intron. J. Mol. Biol. 219: 415-428.

Joyce, G.F., G. van der Horst, and T. Inoue. 1989. Catalytic activity is retained in the Tetrahymena group I intron despite removal of the large extension of element P5. Nucleic Acids Res. 11: 7879-7889.

Kandels-Lewis, S. and B. Séraphin. 1993. Role of U6 snRNA in 5 ' splice site selection. Science 262: 2035-2039.

Kumar, S., N.D. Sharma, R.J.H. Davies, D.W. Phillipson, and J.A. McCloskey. 1987. The isolation and characterisation of a new type of dimeric adenine photoproduct in UV-irradiated deoxyadenylates. Nucleic Acids Res. 15: 1199-1215.

Latham, J.A. and T.R. Cech. 1989. Defining the inside and outside of a catalytic RNA molecule. Science 245: 276-282.

Lerner, M.R., J.A. Boyle, S.M. Mount, S.L. Wolin, and J.A. Steitz. 1980. Are snRNPs involved in splicing? Nature 283: 220 224.

Lesser, C.F. and C. Guthrie. 1993. Mutations in U6 snRNA that alter splice site specificity: Implications for the active site. Science 262: 1982-1988.

Michel, F. and B. Dujon. 1983. Conservation of RNA secondary structure in two intron families including mitochondrial-, chloroplast- and nuclear-encoded members. EMBO J. 2: 33 38.

Michel, F. and E. Westhof. 1990. Modelling of the three-dimen- sional architecture of group I catalytic introns based on comparative sequence analysis. J. Mol. Biol. 216: 585-610.

Michel, F., M. Hanna, R. Green, D.P. Bartel, and J.W. Szostak. 1989a. The guanosine binding site of the Tetrahymena ribozyme. Nature 342: 391-395.

Michel, F., K. Umesono, and H. Ozeki. 1989b. Comparative and functional anatomy of group II catalytic introns. Gene 82: 530.

Muller, M.W., R.J. Schweyen, and C. Schmelzer. 1988. Selection of cryptic $5^{\prime}$ splice sites by group II intron RNAs in vitro. Nucleic Acids Res. 16: 7383-7395.

Newman, A.J. and C. Norman. 1992. U5 snRNA interacts with exon sequences at $5^{\prime}$ and $3^{\prime}$ splice sites. Cell 68: 743-754.

Perea, J. and C. Jacq. 1985. Role of the $5^{\prime}$ hairpin structure in the splicing accuracy of the fourth intron of the yeast cob-box gene. EMBO J. 4: 3281-3288.

Price, J.V. and T.R. Cech. 1988. Determinants of the 3' splice site for self-splicing of the Tetrahymena pre-rRNA. Genes \& Dev. 2: 1439-1447.

Price, J.V., J. Engberg, and T.R. Cech. 1987. 5' Exon requirement for self-splicing of the Tetrahymena thermophila pre-ribosomal RNA and identification of a cryptic $5^{\prime}$ splice site in the 3' exon. I. Mol. Biol. 196: 49-60.

Pyle, A.M., F.L. Murphy, and T.R. Cech. 1992. RNA substrate binding site in the catalytic core of the Tetrahymena ribozyme. Nature 358: 123-128.

Saenger, W. 1984. Principles of nucleic acid structure. SpringerVerlag, New York.

Séraphin, B., L. Kretzner, and M. Rosbash. 1988. A U1 snRNA:pre-mRNA base pairing interaction is required early in yeast spliceosome assembly but does not uniquely define the 5' cleavage site. EMBO I. 7:2533-2538.

Siliciano, P.G. and C. Guthrie. 1988. 5' splice site selection in yeast: Genetic alterations in base-pairing with $U 1$ reveal additional requirements. Genes \& Dev. 2: 1258-1267.

Sontheimer, E.J. and J.A. Steitz. 1993. The U5 and U6 small nuclear RNAs as active site components of the spliceosome. Science 262: 1989-1996.

Stannard, B.S. and G. Felsenfeld. 1975. The conformation of polyriboadenylic acid at low temperature and neutral $\mathrm{pH}$. A single-stranded rodlike structure. Biopolymers 14: 299307.

Strobel, S.A. and T.R Cech. 1993. Tertiary interactions with the internal guide sequence mediate docking of the $\mathrm{P} 1$ helix into the catalytic core of the Tetrahymena ribozyme. Biochemistry 32: 13593-13604.

- 1994. Translocation of an RNA duplex on a ribozyme. Nature Struct. Biol. 1: 13-17.

Tanner, N.K. and T.R. Cech. 1987. Guanosine binding required for cyclization of the self-splicing intervening sequence ribonucleic acid from Tetrahymena thermophila. Biochemistry 26: 3330-3340.

Wassarman, D.A. and J.A. Steitz. 1992. Interactions of small nuclear RNAs with precursor messenger RNA during in vitro splicing. Science 257: 1918-1925.

Winter, A.J., M.J.A. Groot-Koerkamp, and H.F. Tabak. 1992. Splice site selection by intron al3 of the COX1 gene from Saccharomyces cerevisiae. Nucleic Acids Res. 20: 38973904.

Young, B., D. Herschlag, and T.R. Cech. 1991. Mutations in a nonconserved sequence of the Tetrahymena ribozyme increase activity and specificity. Cell 67: 1007-1019.

Yu, Y.-T., P. Maroney, and T. Nilsen. 1993. Functional reconstitution of U6 snRNA in nematode cis- and trans-splicing: U6 can serve as both a branch acceptor and a 5' exon. Cell 75: 1049-1059. 
Zaug, A.J. and T.R. Cech. 1986. The intervening sequence RNA of Tetrahymena is an enzyme. Science 231: 470-475.

Zaug, A.J., P.J. Grabowski, and T.R. Cech. 1983. Autocatalytic cyclization of an excised intervening sequence RNA is a cleavage-ligation reaction. Nature 301: 578-583.

Zaug, A.J., J.R. Kent, and T.R. Cech. 1984. A labile phosphodiester bond at the ligation junction in a circular intervening sequence RNA. Science 224: 574-578.

Zaug, A.J., C.A. Grosshans, and T.R. Cech. 1988. Sequencespecific endoribonuclease activity of the Tetrahymena ribozyme: Enhanced cleavage of certain oligonucleotide substrates that form mismatched ribozyme-substrate complexes. Biochemistry 27: 8924-8931.

Zhuang, Y. and A.M. Weiner. 1986. A compensatory base change in U1 snRNA suppresses a $5^{\prime}$ splice site mutation. Cell 46: 827-835. 


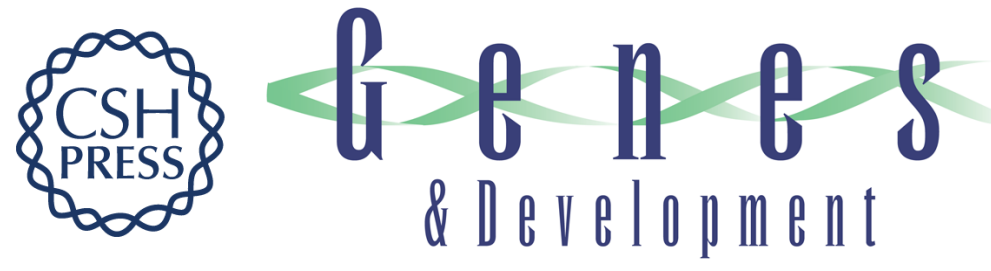

\section{A tertiary interaction in the Tetrahymena intron contributes to selection of the 5 ' splice site.}

W D Downs and T R Cech

Genes Dev. 1994, 8:

Access the most recent version at doi:10.1101/gad.8.10.1198

References This article cites 56 articles, 15 of which can be accessed free at:

http://genesdev.cshlp.org/content/8/10/1198.full.html\#ref-list-1

License

Email Alerting

Service

Receive free email alerts when new articles cite this article - sign up in the box at the top right corner of the article or click here.

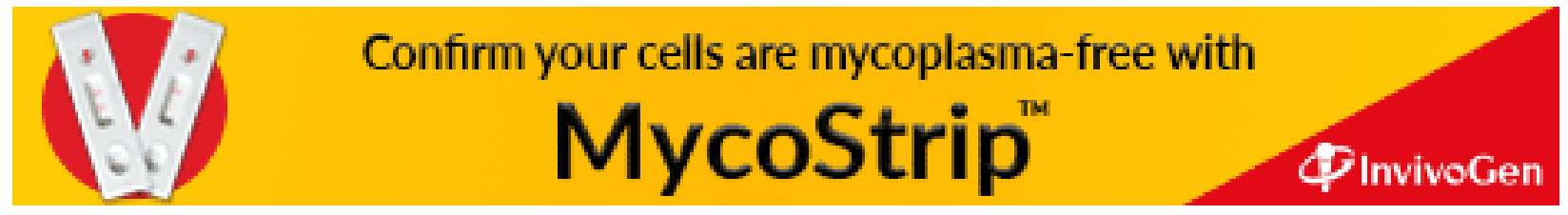

